\title{
Bankruptcy Prediction for Innovative Companies
}

\author{
Ivan Lobeev \\ Business Analyst, Ramax international, Moscow, Russia, \\ ivanlobeev@gmail.com, $\underline{\text { ORCID }}$
}

\section{Abstract}

The main purpose of this article is to identify the best neural network model algorithm and relevant set of variables for predicting financial distress/bankruptcy in innovative companies. While previous articles in this area considered neural network analysis for large companies from primary sectors of the economy, we take the novel approach of examining the less-explored area of innovative companies.

First, we complete a comprehensive review of the relevant literature in order to define the best configuration of factors which can influence bankruptcy, network architecture and learning methodology. We apply our chosen method to a sample of companies from around the world, from industries which are considered innovative, and identify the dependence of bankruptcy probability on a set of factors which are reflected in the financial data of a company.

Our evaluation is based on the financial data of 300 companies - 50 of them are bankrupts, and 250 are 'healthy'. Our results represent the set of relevant factors for bankruptcy prediction and the appropriate neural network. We have applied a total of 19 factors characterising efficiency, liquidity, profitability, sustainability, and level of innovation. Our proposed analysis is appropriate for all sizes of companies. We provided two models in order to cater for the most confidence in terms of obtained results.

The total predictive ability of the model developed in our research is almost $98 \%$, which is extremely efficient, and corresponds to the results of the most modern methods. Both approaches demonstrated almost the same level of influence of factor groups on final bankruptcy probability.

Keywords: bankruptcy, innovative companies, multivariate discriminant analysis, bankruptcy prediction, efficiency, liquidity, profitability, sustainability, innovation

For citation: Lobeev, I. Bankruptcy Prediction for Innovative Companies. Korporativnye finansy = Journal of Corporate Finance Research.2021;15(4):36-55. doi: https://doi.org/10.17323/j.jcfr.2073-0438.15.4.2021.36-55 


\section{Introduction}

At the beginning of the twentieth century, the world economy was faced with a large number of crises. This fact is obviously related to the rapid development of different branches of the economy. World GDP and technological innovation is growing faster than at any previous time in history. As a result, business cycle recessions have destroyed many companies and driven many more to bankruptcy. There are several causes of corporate financial distress and it is a difficult concept to define, but it is possible to reveal factors which can be a signal to impending bankruptcy. The definition of the pre-bankrupt condition is a crucial issue for the timely prevention of distress. There are several models which predict bankruptcy with very high accuracy, however, as we consider in greater detail below, such models are oriented on the basis of large industry sectors such as oil, gas, trading, or the entire economy as a whole. Such models are not effective predictors for companies from the most unsustainable economic sectors, e.g. companies to innovative industries. These companies have the highest bankruptcy risks because they necessitate the exploration of unknown economic areas and the creation of new products without any guarantee of profit. High expenditure in terms of research and development (R\&D) decrease the free cash flow of innovative firms, and can leads to financial unsustainability and higher distress risk, although not necessarily. The high levels of R\&D expenditure can also lead to successful strategic decisions which can improve the company's financial condition. Such expenditure is, in principle, warranted in the innovative sector, as innovative companies invent new technologies, which can improve life quality worldwide. Currently, there are no research studies which contain an adequate model for bankruptcy prediction of innovative companies. This is the reason why the current research is so relevant. The pre-bankrupt condition can be identified by the combination the presence of a set of formal financial factors, and defining this, particularly for innovative companies, is crucial to our task. As such, our research aims to help such innovative companies identify the relevant factors defining a pre-bankrupt condition in their sector.

The main purpose of this article is to choose the best neural network model algorithm and relevant set of factors for predicting the financial distress of innovative companies. Our proposed analysis is appropriate for all sizes of companies. It was conducted because the sample is rather small, and division can spoil the network studying.

To complete our task, it is necessary to address a set of issues: to analyse the research studies of previous years from the earliest to the latest, and to trace the development of knowledge in this sphere; to gather the relevant data for so-called 'healthy' companies and for bankrupt companies and identify an appropriate point indicating the beginning of financial distress; to convert this raw data to a data set which is convenient for analysis, to delete the missing values and to calculate the financial ratios and other variables which constitute factors of innovative corporate bankrupt- cy; to construct neural networks with different settings (e.g. according to architecture, factors, learning algorithm) and choose the most relevant algorithm with the highest forecasting accuracy and the lowest error; and finally, to construct a financial distress prediction model.

The object of this research is a sample of companies from around the world, from industries which are considered innovative. The subject of this article is the dependence of bankruptcy probability on the set of factors which are reflected in the financial data of a company.

The novelty of current research is that the previous articles in this area considered neural network analysis for large companies from primary sectors of the economy. These tend to be complicated models, which mix different tools such as neural network, regression analysis, multivariate discriminant analysis (MDA), and genetic algorithms, but innovative companies, being the most affected by market fluctuations, have not been adequately considered. On a related note, we selected a global sample of companies, because when restricted to the Russian economy alone, there are not enough companies to run the appropriate analysis. We will analyse the provided data of 300 companies. 50 of them are bankrupts, and 250 are 'healthy'. Our results represent the set of relevant factors for bankruptcy prediction and the appropriate neural network.

\section{Literature review}

Since 1968, when the first and the most famous research paper in financial distress forecasting appeared [1-2], methodological approaches in this sphere have run in two directions: market-based methods and accounting based methods.

\section{The market-based models}

The market-based approach usually applies the Black Scholes formula [3] in terms of call-option as a foundation for further analysis. The assumptions behind this method involve a classical version of option valuation theory: i.e. the value of the main variable corresponds to the Brownian motion value of dependent variables as normally distributed. The main factors for market-based models include: firm value, equity value, debt value, volatility of firm value, risk-free rate, and dividend payments.

As can be noticed all the variables can be seen by all people from the financial market. This is the reason such models are titled 'market-based'. The mathematical apparatus can be very complicated for such models, but the idea of defining the financial condition of a company is very straightforward. Quite simply, there is some threshold combination of variable values which gives the estimation of bankruptcy probability. Merton [4] created the first model with a minimal factor set, and subsequently many researchers improved upon this model by imposing new factors [5-9]. The main advantages of this group of methods are the necessity for small amounts of inputted information, availability for almost all people and also presence of a large 
number of special computer programs, which allows to calculate financial distress probability very quickly. The disadvantage of such methods is a low predictive ability and an incapability to vary according to different external conditions.

\section{The accounting-based models}

The second type of bankruptcy prediction model is accounting based. Two scientists developed this forecasting direction almost at the same time: Beaver [10] and Altman [1]. Altman's article became so popular that modern researchers often refer to it. Altman's approach used multivariate discriminant analysis (MDA) and ran a regression with five factors. The main factors for accounting-based models includes: profit / total assets; profit + taxes / total assets; sales / total assets; equity /liability; working capital / total assets.

After estimating the coefficient for each of these factors, Altman calculated the Z-score and compared it with critical statistics to make a conclusion about financial sustainability of a particular company. This article has motivated other financial distress experts to create predictive models [11]. Extended models have been in development for a long time, and many additional factors were included in MDA. Different factor combinations have been tested, but the predicting accuracy has not exceeded $75-80 \%$.

The described methods have the advantage of simplicity in calculating bankruptcy score and interpreting results. They can be applied across a range of company types, industries, or economic conditions and can accommodate the inclusion of new factors for multivariate discriminant analysis. Some disadvantages of this method are that different samples can show very different results and on average demonstrate quite low predictive ability. However, this does not mean that such models are useless- in fact, the factors used to build them can be used to develop more advanced predictive approaches. The same factors are used in almost all papers devoted to financial distress prediction with neural network analysis as they give the highest accuracy in forecasting. In this paper, the development of artificial network analysis is considered the most effective method to approach evaluation.

\section{The neural network models}

The usage of neural networks for analysing financial distress prediction began with the article of Odom and Sharda [12]. The researchers built a neural network with 2-layer perceptron (MLP) and applied the learning algorithm of backpropagation. The input factors were the same as in the modified Altman model. The factors used in the modified Altman's bankruptcy model include: EBIT / total assets; equity / debt; sales / total assets; working capital / total assets; retained earnings / total assets.

The purpose of Odom and Sharda's article was to compare the predictive ability with the factor set of described neural network and classical MDA model. The data sample was not so large. It comprises 129 large companies from Moody's database, one half of which are bankrupts, with the rest being 'healthy'. The empirical study results demonstrate the superiority of neural network-based analysis to the MDA model in such aspects as prediction accuracy (79\% against $75 \%$ ), and the robustness of received estimations.

This research showed that there is a more efficient method than the MDA. For the next five years, scientists experimented with changing the factor combination and adding factors to improve the neural network model [13-15]. As a result, the authors managed to increase the predictive accuracy to approximately $80-83 \%$.

It was obvious that corporate bankruptcy prediction required innovative, more convenient approaches to neural network analysis, and the thrust of the research focused on the integration of existing forecasting methods. Lee, Han \& Kwon [16] combined neural networks, MDA, and decision trees in their research. They distinguished and compared the predictive ability of five models: MDA, decision trees, neural network with factor selection algorithm based on MDA, neural network with factor selection algorithm based on decision tree, and neural network with a self-organising Fisher's maps (SOFM). MDA and decision trees demonstrate very poor accuracy, about $70-75 \%$. The main interest of their research is the comparison of the quality of three neural network models. The novelty of the research paper is its introduction of an unsupervised learning algorithm. It is widely recognized that in general there are two types of learning algorithm - supervised and unsupervised. The supervised algorithm is the most popular for forecasting. The backpropagation (BP) and learning vector quantisation (LVQ) are related to the supervised method. While SOFM is unsupervised. Lee, Han \& Kwon invented a new methodology, combining the SOFM and LVQ, and this model has demonstrated its superiority in comparison to MDA and decision trees-based neural networks. The algorithm of this innovative approach is rather complicated. At the first stage, the neural network with SOFM algorithm factors are allocated to clusters which can reflect almost the same influence on financial sustainability according to input data. The second stage is the neural network analysis with an LVQ learning algorithm. This is needed for choosing the most appropriate variables inside each cluster. The third stage of analysis entails constructing the neural network for defining the most relevant clusters for the sample. The last stage of empirical analysis involves drawing conclusions about whether the company is bankrupt or not. This research was based on a sample of Korean firm data from 1979 to 1992. All companies were arranged according to size and by the value of assets. 58 factors were taken from six spheres: profitability, firm growth, cash flow, stability, activity, and credibility. As a result, the forecasting accuracy of $80.5 \%$ was identified, which is greater than other approaches.

The research of Jo, Han and Lee [17] once again proved the superiority of neural networks. They provided a comparison of MDA, case-based approach and neural network. Where previous researchers used linear or hyperbolic tangent activation function, Jo \& Han used sigmoid, which is 
known today as the greatest resource for predicting bankruptcy. Another novelty is that authors have constructed 36 samples with the data from 1991-1993 for Korean companies. They vary in terms of forecasting period from one to three years. This represents the first research study taking in account the number of years before bankruptcy. As a result, the best forecasting accuracy was rated at a level of approximately $84 \%$.

Yang, Platt and Platt [18] proposed a new type of neural network prediction architecture for financial distress. If all previous authors use multilayer perceptron (MLP) and varied only the learning algorithm, Yang, Platt and Platt used probabilistic neural network (PNN) which is one of a kind of radial basic function (RBF). This type of network is known to be better suited for classification issues. The data sample consists of gas and oil industry companies from the USA over the period of 1984-1989. This methodology exceeds the predictive power of MLP neural networks and especially MDA.

A significant research study which answers questions about the best existing neural network model is the paper of Charalambous, Charitou \& Kaourou [19]. They built neural network to define the influence of 7 factors. Factors from the Charalambous, Charitou \& Kaourou model include current liabilities / total assets; cash / total assets; long term debt / total assets; operating income; change in cash flow from operations / equity value, change in account receivables; working capital / equity value.

These factors include a comparison of a feedforward neural network architecture with a backpropagation learning algorithm, with a conjugate gradient algorithm, the radial basis function architecture (RBF) with the backpropagation algorithm and the MLP architecture with a combination of SOFM and LVQ. As a result, almost $90 \%$ accuracy was obtained for this neural network type. According to the authors, this approach is the most accurate currently in existence.

A number of other research studies approve the fact of superiority of neural network prediction against MDA and other approaches. A Spanish sample was used by Olmeda and Fernandez [20] for predicting financial distress by MDA, decision trees, and an MLP neural network. The latter showed the greatest forecasting power, with $83 \%$. The same accuracy was obtained by Piramuthu, Raghavan and Shaw [21] which analysed the financial sector with MLP. Zhang [22] created the MLP with three hidden layers to predict bankruptcy for Korean firms with Altman's factors. They managed to produce results at $88 \%$ accuracy.

Koh and Tan's research [23] studies MLP neural network and profit regression analysis. This concludes that the predictive power is the same for both methods at a $92 \%$ level. Hybrid neural network models were constructed in papers of Yang [18] and Yim and Mitchell [24]. Both research studies obtained 95\% accuracy. Data from Hungarian companies was introduced in the paper by Virag and Cristofs [25] in the context of a model quality comparison, using a neural network and a math statistical model. The neural network showed superior results.

Tsai and $\mathrm{Wu}$ [26] considered the use of an MLP neural network with one hidden layer. Researchers tested different nodes on this layer, numbered from 1 to 13 . The analysis result demonstrates superiority of the 3-nodes MLP to other cases.

Kim and Kang [27] provided a comparison of an MLP neural network with three different learning algorithms: backpropagation, boosting, and bagging. The data sample was composed of Korean companies, and more than 30 factors were selected from seven types of firm's information, including: size, liquidity, leverage profitability, debt coverage, activity, and capital structure. As a result, the bagging algorithm produced the best quality results.

Zhou, Lai and Yu [28] included macroeconomic indicators beside a firm's financial ratios in their analysis. They compare MLP neural networks in the presence of macroeconomic variables. The set of variables are show in Table 1 . The extended model demonstrated superior results in accuracy.

Table 1. Factors from Zhou, Lai and Yu model

\begin{tabular}{|c|c|c|}
\hline Equity / Total Assets & Dividend & Sales / Cash \\
\hline Net Income / Net Sales & Total Debt / Total Assets & Current Liabilities / Total Assets \\
\hline Cash Flow / Total Assets & Current Assets / Total Assets & Long Term Debt / Total Assets \\
\hline Cash Flow / Total Debt & Retained Earnings / Total Assets & ROA \\
\hline Current Ratio & Working Capital / Total Assets & Current Assets / Current Liabilities \\
\hline Cash / Total Assets & Total Assets & Net Income / Equity \\
\hline Net Income / Sales & Current Assets / Sales & Working Capital / Sales \\
\hline Fixed Assets / (Equity + Long Term Debt) & GDP & Consumer Price Index \\
\hline
\end{tabular}

Personal Income Index

Money Amount 
Kasgari et al. [29] conducted another comparison of an MLP neural network with a probit-regression model. They use only four factors, including sales divided by current ratio, operating income divided by sales, current assets divided by total assets, and total debt divided by total liability. The neural network correctly predicted $87 \%$ of bankruptcies, which is higher than the figure for the probit model.

Makeeva and Bakurova [30] compared a neural network with logistic regression using factors from four spheres, including financial leverage, profitability, liquidity, and turnover with a sample of Russian oil and gas industry companies. The most important parameters reflected profitability. As a result, the neural network gave 98\% accuracy, better than the logistic model.

Yasnitsky et al. [31] ran a neural network analysis checking the probability of bankruptcy in banks. There were 15 qualitative and quantitative parameters. The accuracy of this model is higher than $90 \%$, which is a great result for such an inconsistent industry.
Azayite and Achchab [32] used data from Moroccan companies and a factor set from a modified Altman's model to construct a hybrid model. The MDA regression helped to identify the best factors for a neural network. An MLP with a backpropagation learning algorithm helped to build the financial distress function, and the neural network calculated the bankruptcy probability with an SOFM algorithm. The distinguishing feature of this research is that the failure of firms has been predicted in 1,2 and 3 years before the initial moment of bankruptcy. The hybrid model allowed for obtaining the best result for the Altman's factor set. The final prediction accuracy is approximately $95 \%$.

Azadnia, Siabi and Motameni [33] tested the fuzzy neural network approach on a data sample of gas and oil companies from Tehran, and produced a prediction accuracy of 99\%. They run an MLP with 3 hidden levels. More than 15 factors from four areas (productivity, asset quality, profitability, and sustainability) were selected.

The main research studies in neural network bankruptcy prediction were considered above. The summary of models, data samples, and results are introduced in Table 2.

Table 2. Summary of existing models

\begin{tabular}{|c|c|c|c|c|}
\hline Year & Authors & Approach & Data set & Results \\
\hline 1990 & Odom \& Sharda & MDA vs. MLP neural network & $\begin{array}{l}129 \text { companies from } \\
\text { Moody's database }\end{array}$ & $\begin{array}{l}\text { MLP }(79 \%) \text { is better } \\
\text { than MDA }\end{array}$ \\
\hline 1996 & $\begin{array}{l}\text { Lee, Han \& } \\
\text { Kwon }\end{array}$ & $\begin{array}{l}\text { MDA vs. decision tree vs. MLP based } \\
\text { on MDA and decision tree with } \\
\text { SOFM and LVQ learning algorithm }\end{array}$ & $\begin{array}{l}140 \text { Korean } \\
\text { companies }\end{array}$ & $\begin{array}{l}\text { MLP with SOFM and } \\
\text { LVQ is better }(80.5 \%)\end{array}$ \\
\hline 1997 & Jo \& Han & $\begin{array}{l}\text { Case-based vs. MDA vs. MLP } \\
\text { network }\end{array}$ & $\begin{array}{l}\text { Korean companies } \\
(1991-1993)\end{array}$ & MLP is better $(83.8 \%)$ \\
\hline 1998 & Yang \& Platt & $\begin{array}{l}\text { PNN with backpropagation vs. MLP } \\
\text { network based on MDA }\end{array}$ & $\begin{array}{l}122 \text { oil companies } \\
\text { from USA (1984- } \\
1989)\end{array}$ & PNN is better $(84.1 \%)$ \\
\hline
\end{tabular}

MLP with SOFM and LVQ vs.

2000 Charalambous \& RBF vs. Feedforward network with Charitou backpropagation vs. Feedforward network with conjugate algorithm
139 pairs of USA Feedforward network companies with conjugate is

better $(89.6 \%)$

2012

Kasgari \&

MLP

Iranian data set

(87\%) accuracy

$2012 \quad$ Makeeva \&

MLP network vs. logistic regression

Gas \& oil sector

MLP is better (98\%)

$2016 \quad$ Azayite \& Achchab

MLP with MDA and SOFM algorithm Moroccan companies

(95\%) accuracy 


\section{The 'innovativeness' factor}

As was mentioned above, the distinguishing feature of the present paper is the forecasting of bankruptcy, and the application of this forecast to innovative companies. It is very important to explain the rationale behind company selection. In this research, only innovative industries were selected for analysis. The following list of relevant industry sectors were taken from the article by Makeeva and Khugaeva [34] and standard industrial classification: drugs; computer and office equipment; electric transmission and distribution equipment; electrical industrial apparatus; household appliances; electric lighting and wiring equipment; household audio and video equipment; communication equipment; electronic components and accessories; miscellaneous electrical machinery and equipment; telephone communication; and computer programming, data processing and other computer related services; research, development and testing services.

The next question concerns the determination of some special factors, which can be significant for innovative companies in particular. Unfortunately, there are no research studies which look at the bankruptcy of innovative companies' using a neural network, but some do exist which use an MDA and costs of financial distress as analytical tools. The first mention of innovative firms in terms of bankruptcy probability was made by Opler and Titman [35]. They examined the financial distress of innovative companies, but there were no special factors which distinguished hightech companies.

A more relevant research method is offered by Zhang [22]. He tried to answer the question about the presence of relationship between the R\&D expenditure and bankruptcy probability. The Altman's Z-score was used for this purpose. Authors estimated four regressions with four different innovative company's indicators, including R\&D expenditure divided by total assets, by sales, by number of employees, and by R\&D capital. R\&D capital was also used in the paper by Jo, Han and Lee [17]. The formula for R\&D capital is following:

$$
\begin{aligned}
& \mathrm{R} \& \mathrm{DCap}=\mathrm{R} \& \mathrm{D}_{\mathrm{t}}+0.8 \mathrm{R} \& \mathrm{D}_{\mathrm{t}-1}+0,6 \mathrm{R} \& \mathrm{D}_{\mathrm{t}-2}+ \\
& +0,4 \mathrm{R} \& \mathrm{D}_{\mathrm{t}-3}+0,2 \mathrm{R} \& \mathrm{D}_{\mathrm{t}-4}
\end{aligned}
$$

As can be seen here, the R\&D capital is the sum of $R \& D$ investments in the current year, and in the previous four years with defined weights.

Bulot also analysed the factors of innovative companies' bankruptcy. Besides the classical factors like liquidity and firm size, he used the R\&D investments and change in investment policy like specific innovative factors. As a result,
R\&D investments makes sense in terms of a firm's sustainability.

The major research study which contains the analysis of almost 300,000 firms was described in by Buddelmeyer, Jensen and Webster [36]. This investigated the dependence between a firm's sustainability, investment in innovation, and other company characteristics. The model factors from [36] includes: market factors, which characterise the economy's growth and the environmental conditions; technical efficiency which also includes innovative factors like R\&D expenditure and short-term investment activity; relative profitability of a company within the industry; salary in the company scaled by total assets is a proxy of variable costs; firm's access to finance.

There is no reason to consider these factors in detail, but it is important that innovativeness is used as a bankruptcy factor. The higher the investment in $\mathrm{R} \& \mathrm{D}$, the more stable the company, according to the research results.

Makeeva and Khugaeva [34] estimated the costs of financial distress of innovative companies. They faced the problem of bankruptcy probability evaluation. Four factors for innovative companies were selected, including R\&D expenditure divided by total assets, R\&D expenditure divided by sales, R\&D expenditure divided by number of employees, and R\&D capital, which is defined as the sum of $\mathrm{R} \& \mathrm{D}$ expenditure of previous years, multiply by some coefficient, which was described above.

To sum up, there are a lot of research studies which investigate the impact of a firm's innovativeness on its sustainability and bankruptcy probability, but all of them use regression or MDA analysis, or focus on the costs of financial distress evaluation. The present research, by comparison, mixes a focus on innovativeness with the more powerful neural network analysis.

The different research studies into bankruptcy probability were discussed above. There are a lot of different methodologies for running the neural network analysis, and many factors from different areas of a company's financial results. We will consider the identification and choice of these factors and appropriate methods for empirical analysis.

\section{Methodology and data \\ The bankruptcy factors}

Several models were reviewed above, and in the framework of this research, the most relevant of those factors will now be outlined. Generally, this can be divided into five groups: effectiveness, profitability, sustainability, liquidity, and innovativeness (Table 3 ). 
Table 3. Model factors

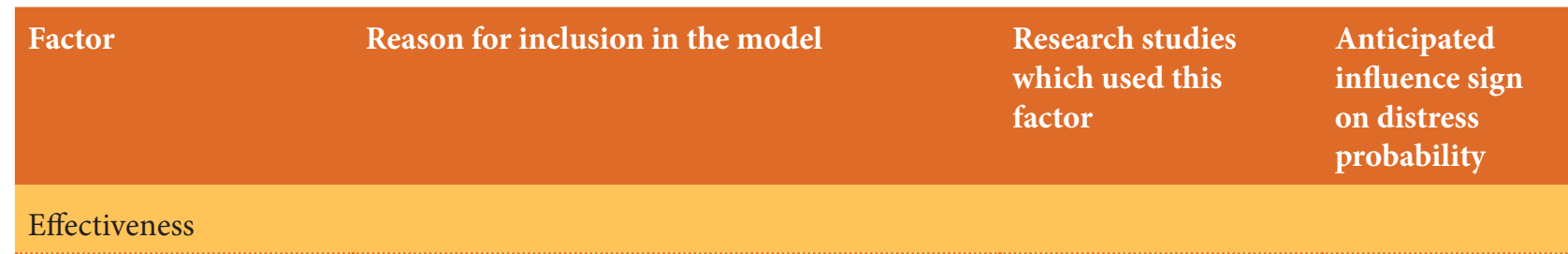

$\begin{array}{lll}\text { The positive mean of this variable means the } & \begin{array}{l}\text { Tudor (2015), } \\ \text { Piramuthu \& }\end{array} \\ \text { frowth rate of net sales growing demand on its product or } & \begin{array}{l}\text { Raghavan (1998), } \\ \text { service, and is a good sign that the company } \\ \text { has a great financial sustainability }\end{array} & \begin{array}{l}\text { Olmeda \& Fernandez } \\ \text { (1997) }\end{array}\end{array}$

This ratio reflects the effectiveness of assets
usage

Ligang \& Lai (2010),

Olmeda \& Fernandez

(1997), Charalambous

\& Charitou (2000)

$\begin{aligned} & \text { Profitability } \\ & \text { Net profit / Equity }\end{aligned}$ These two variables reflect how much money
the assets and equity generate

Charalambous \&

Charitou (2000);

Ligang \& Lai (2010);

Azadnia \& Siabi

(2017); Makeeva \&

Bakurova (2012)

$\begin{array}{ll}\text { Sustainability } & \\ \text { Equity / Fixed Assets } \quad \begin{array}{l}\text { This parameter demonstrates the coverage of } \\ \text { fixed assets by equity, and is associated with } \\ \text { lower sustainability and higher bankruptcy } \\ \text { probability }\end{array}\end{array}$

Working capital / Total assets

Total liability / Total equity

Total liability / Total assets

\section{Ligang \& Lai}

(2010), Kim \& Kang

(2009), Piramuthu

\& Raghavan (1998),

Charalambous \&

Charitou (2000)

Azayite \& Achchab

(2016), Kim \& Kang

(2009), Charalambous

\& Charitou (2000)

\section{Makeeva \& Bakurova}

(2012), Olmeda \&

Fernandez (1997),

Charalambous \&

Charitou (2000) usually associated with greater sustainability of a company and, consequently, with less probability of financial distress
Kasgari \& Divsalar

(2012), Kim \& Kang

(2009), Charalambous

\& Charitou (2000)

\section{Liquidity}

Cash / Current

liabilities

Cash / Total assets
The most liquid asset is cash, which means that greater value of these two ratios associated with greater liquidity and less bankruptcy probability
Azadnia \& Siabi

(2017); Tsai \& Wu

(2008), Piramuthu \&

Raghavan (1998) 


\begin{tabular}{|c|c|c|c|}
\hline Factor & Reason for inclusion in the model & $\begin{array}{l}\text { Research studies } \\
\text { which used this } \\
\text { factor }\end{array}$ & $\begin{array}{l}\text { Anticipated } \\
\text { influence sign } \\
\text { on distress } \\
\text { probability }\end{array}$ \\
\hline $\begin{array}{l}\text { Curent assets / Current } \\
\text { liabilities }\end{array}$ & \multirow{3}{*}{$\begin{array}{l}\text { This parameter group demonstrates the } \\
\text { coverage of quick liabilities, total debt and total } \\
\text { revenue by liquid assets. A greater mean of } \\
\text { these ratios is associated with less bankruptcy } \\
\text { probability }\end{array}$} & \multirow{4}{*}{$\begin{array}{l}\text { Kasgari \& Divsalar } \\
\text { (2012); Ligang \& Lai } \\
\text { (2010), Kim \& Kang } \\
\text { (2009), Charalambous } \\
\text { \& Charitou (2000) }\end{array}$} & - \\
\hline $\begin{array}{l}\text { Current assets / Total } \\
\text { liabilities }\end{array}$ & & & - \\
\hline Current assets / Sales & & & - \\
\hline $\begin{array}{l}\text { Current liabilities / } \\
\text { Equity }\end{array}$ & $\begin{array}{l}\text { Thus parameter has negative influence on } \\
\text { financial sustainability of a company }\end{array}$ & & + \\
\hline \multicolumn{4}{|l|}{ Innovativeness } \\
\hline R\&D / Total assets & \multirow{2}{*}{$\begin{array}{l}\text { The main criteria of innovativeness is R\&D } \\
\text { expenditure, to eliminate the influence of firm's } \\
\text { size, this variable are scaled to total assets and } \\
\text { sales }\end{array}$} & \multirow{4}{*}{$\begin{array}{l}\text { Makeeva \& } \\
\text { Khugaeva(2018), Liu } \\
\text { (2011), Zhang (2005), } \\
\text { Bulot (2015) }\end{array}$} & $+/-$ \\
\hline R\&D / Sales & & & $+/-$ \\
\hline \multirow{2}{*}{$\begin{array}{l}\text { RD Capital / Total } \\
\text { Assets }\end{array}$} & $\begin{array}{l}\text { RD Capital }=R \& D \operatorname{Exp}(t)+0,8 R \& D \operatorname{Exp}(t-1) \\
+0,6 R \& D \operatorname{Exp}(t-2)+0,4 R \& D \operatorname{Exp}(t-3)+ \\
0,2 R \& D \exp (t-4)\end{array}$ & & \multirow[t]{2}{*}{$+1-$} \\
\hline & $\begin{array}{l}\text { This is a cumulative variable of R\&D } \\
\text { expenditure also scaled by the size }\end{array}$ & & \\
\hline
\end{tabular}

The above analysis on the anticipated impact of each factor on bankruptcy probability allows us to make a hypothesis about the total influence on each factor's group on final forecasting.

Hypothesis 1. The effectiveness of a company is negatively related to distress probability for innovative firms.

Hypothesis 2. The profitability of a company has the same impact sign.

Hypothesis 3. Sustainability has a negative impact on financial distress probability.

Hypothesis 4. The liquidity of a company has the same impact sign.

The innovativeness of a company does not have an obvious impact on performance indicators. Higher R\&D expenditure usually affects free cash flow, and as a result the company can become incapable of making necessary payments and can face bankruptcy. On the other hand, greater $R \& D$ expenditure may help the firm's management to invent some new product or make some improvements in production processes which can enable growth in the firm's market position and, as a result, outperform its financial variables. Consequently, the probability of bankruptcy can decrease. In the framework of this paper, the following hypothesis is proposed:

Hypothesis 5. Higher innovativeness is positively related to bankruptcy probability, particularly for companies from innovative industries.

\section{The neural network's learning}

This section is considers different neural network methodologies. The neural network is a model of the neural system of a living organism. In contrast to parametric approaches to forecasting, when the connection between different elements is obvious, the network can identify dependence in cases where it is not straightforward. The network has the ability to learn based on real data in order to successfully forecast further work. Neural networks can be divided into two groups: 'supervised' and 'unsupervised. The majority of articles considered above used the supervised method. The most popular are the backpropagation (BP) algorithm and learning vector quantisation (LVQ). As the unsupervised algorithm is usually self-organising, Fisher's map is used (SOFM). Several other learning algorithms exist besides these, but they are usually used for other issues, and rarely for forecasting bankruptcy. Moreover, they demonstrate less predictive ability and less robustness in terms of result. The classic BP algorithm was used in terms of network construction because the data have been taken for different sizes and company types. There is one danger in the use of the BP algorithm, which is overlearning. This situation is where the model becomes too formal and inflexible and can only classify bankruptcy according to one factor (whereas it is necessary to take all factors into account). The network usually tries to minimise the error, but while searching for the minimum error point it can overlearn. To eliminate this issue, it is necessary to restrict the learning time and check the model quality according to independent data. 


\section{Types of neural network architecture}

\section{The multilayer perceptron (MLP)}

Another issue which should be taken into account is network architecture. There are several types, but the most popular is multilayer perceptron (MLP). It has at least three layers: input, output, and hidden. The input layer consists of factors and take a data with some weight. The next step involves transferring this weighted data to the hidden layer with an activation function. The neurons involved in the hidden layer can then connect with the output layer with another activation function. The output layer calculates the final mean, and a researcher can make a decision about the financial condition of a company. Neural networks usually contain one hidden layer, but in some cases two of them are needed. Three or more layers are used very rarely. The MLP can use BP, conjugate gradient, or delta-delta as a learning algorithm. The most common is BP. It can use four common activation function types: sigmoid, hyperbolic tangent, threshold, and linear function. The most popular is sigmoid function. This methodology has the main disadvantage of tending towards overlearning, but is consistent in application. This means that MLP greatly analyse the data with large number of input factors.

\section{Radial basis function (RBF)}

This function type has exactly one hidden layer with radial function, which produces a Gaussian function. The advantages of RBF are that it has only one hidden layer and it is not necessary to select the number of these layers, also such network entails less learning time, which substantially decreases the possibility of overlearning. The main disadvantage of this architecture type is the sensitivity to the number of factors on input layer. As a result, the network quality usually falls.

\section{Probabilistic neural network (PNN)}

Yang, Platt and Platt [18] used the PNN and compared its effectiveness with MDA and MLP. They conclude the superiority of the PNN. This neural network type looks like on $\mathrm{RBF}$ - it also has only one hidden level and has the same radial function as activation. PNN has a probability of belonging to some category in contrast to RBF. This architecture is the best for solving the classification issues. It seems this network type is the best for our current research, but poses the disadvantage that PNN can result in low forecast quality because the great number of factors mitigates against the choice of MLP, which is universal and more suitable for current issue.

\section{Other network architecture types}

It is necessary to consider other widespread neural network types, including general regression (GRNN), linear (LNN) and the self-organising Kohonen's network. The GRNN is not suitable for bankruptcy prediction. LNN is very simple for this issue. The Kohonen's algorithm was used in some papers on this topic but it is very difficult to apply, and not needed for the present research framework.

It is quite challenging to construct the best neural network for a particular issue. Because of this, several types of architecture and activation functions were used to build the most appropriate network. MLP perceptron was tested with 1 or 2 hidden layers with different numbers of neurons, as well as various activation functions: sigmoid, hyperbolic tangent, and the Softmax function from SPSS. To run the network, the computer program IBM SPSS Statistics 24 was used.

\section{Data description}

For our neural network analysis, we examined data from 300 companies around the world from the innovative sectors. The sample is divided into two groups: bankrupts and 'healthy' companies. There are 51 bankrupts (17\%) and 249 'healthy' firms (83\%).

In previous studies an equal proportion of company types was used, but it decreases the model's robustness depending on the choice of sample. Neural networks can predict bankruptcy only where there is an obvious feature of a bankruptcy available to identify. The greater fraction of non-bankrupts with increasing number of observations provide a higher model quality. This is true, because a neural network that can properly classify a bankrupt by a large number of unauthorised bankruptcies is more preferable. Data has been collected for a 6 year period. Thus, we have data on bankrupts for the period of 2012-2017. This long duration was selected because there are not so many companies in these innovative industries which faced with financial distress. The division of companies by bankruptcy is as follows: $2012-15,2013-1,2014-8,2015-4,2016$ - 5, $2017-8$, non-bankrupts - 249 .

The division by country is as follows: 126 companies (42\%) are from the USA, 66 (22\%) - from Canada, 36 (12\%) from China, 21 (7\%) - from Japan, 15 (5\%) - from South Korea, 36 (12\%) - from other countries.

The data sample is divided between 10 industries: computer programming - 117 companies, drugs - 90 companies, communication equipment -30 , electric transmission and distribution equipment - 18, electronic components and accessories - 15, electrical industrial apparatus - 9, R\&D and testing services -6 , computer and office equipment -6 , electric lighting and wiring equipment -6 , and household audio and video equipment -3 (Figure 1).

The observations above are used for our neural network learning and testing sample construction. A total of 37 factors were selected that could affect the likelihood of bankruptcy. The data were taken for two years: a year before the bankruptcy and a year of bankruptcy. Variables and their descriptive statistics are demonstrated in Table 4. 
Figure 1. Data sample division by industries

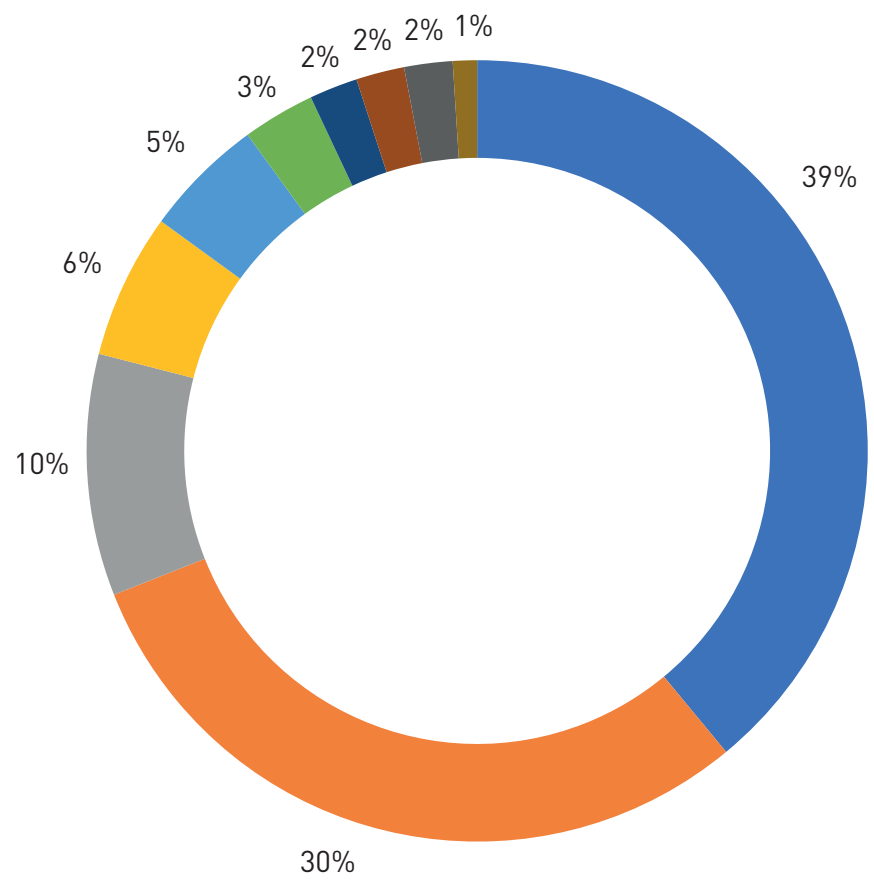

- Computer programming

Drugs

Communication equipment Electric transmission and distribution equipment Electronic components and accessories

Electrical industrial apparatus

R\&D and testing services

- Computer and office equipment

- Electric lighting and wiring equipment

Table 4. Descriptive statistics

\begin{tabular}{|c|c|c|c|c|c|c|}
\hline \multicolumn{7}{|c|}{ Descriptive statistics } \\
\hline & & $\mathbf{N}$ & Min Value & Max Value & Mean & St. deviation \\
\hline BANKRUPT & Bankruptcy & 300 & 0 & 1 & .17 & .376 \\
\hline GROW_NS & Growth rate of net sales & 295 & -.88 & 11.55 & .1524 & .79154 \\
\hline GROW_NS1 & Growth rate of net sales -1 & 295 & -3.68 & 4.93 & .0867 & .49046 \\
\hline SAL_TA & Sales / Total assets & 300 & .00 & 8.06 & .8303 & .85799 \\
\hline SAL_TA1 & Sales / Total assets -1 & 300 & .00 & 18.48 & .8905 & 1.31510 \\
\hline NP_E & Net profit / Equity & 300 & -683.0 & 210.37 & -5.688 & 55.04891 \\
\hline NP_E1 & Net profit / Equity - 1 & 300 & -172.6 & 11.71 & -.7521 & 10.30278 \\
\hline $\mathrm{NP} \_\mathrm{A}$ & Net pofit / Total assets & 300 & -11.92 & 3.63 & -.2875 & 1.23403 \\
\hline NP_A1 & Net pofit / Total assets - 1 & 300 & -19.19 & 3.63 & -.3107 & 1.53507 \\
\hline GP_SAL & Gross profit / Sales & 295 & -2.90 & 5.65 & .4087 & .47648 \\
\hline GP_SAL1 & Gross profit / Sales - 1 & 295 & -2.90 & 5.65 & .4154 & .47369 \\
\hline NP_SAL & Net profit / Sales & 299 & -357.8 & 1.61 & -2.606 & 22.14058 \\
\hline NP_SAL1 & Net profit / Sales -1 & 299 & -357.8 & 1.61 & -2.529 & 21.88535 \\
\hline E_FA & Equity / Fixed assets & 295 & -2485 & 433.33 & 1.0213 & 153.47650 \\
\hline E_FA1 & Equity / Fixed assets - 1 & 295 & -195.5 & 433.33 & 9.8318 & 42.83228 \\
\hline WC_A & Working capital / Total assets & 300 & -12.00 & .86 & .1071 & 1.21998 \\
\hline WC_A1 & $\begin{array}{l}\text { Working capital / Total assets } \\
-1\end{array}$ & 300 & -17.36 & .86 & .0302 & 1.63675 \\
\hline L_E & Total liability / Total equity & 300 & -171.4 & 52.28 & .4164 & 10.80219 \\
\hline L_E1 & $\begin{array}{l}\text { Total liability / Total equity } \\
-1\end{array}$ & 300 & -12.50 & 55.87 & 1.2758 & 5.06943 \\
\hline
\end{tabular}




\begin{tabular}{|c|c|c|c|c|c|c|}
\hline \multicolumn{7}{|c|}{ Descriptive statistics } \\
\hline & & $\mathbf{N}$ & Min Value & Max Value & Mean & St. deviation \\
\hline$L_{-} A$ & Total liability / Total assets & 300 & .01 & 14.13 & .7313 & 1.60268 \\
\hline L_A1 & Total liability / Total assets - 1 & 300 & .01 & 18.05 & .7952 & 1.92696 \\
\hline CASH_CL & Cash / Current liabilities & 300 & 0 & 19.61 & 1.0662 & 1.94487 \\
\hline CASH_CL1 & Cash / Current liabilities - 1 & 300 & 0 & 25.57 & 1.1635 & 2.18065 \\
\hline CASH_A & Cash / Total asset & 300 & 0 & .88 & .1984 & .17610 \\
\hline CASH_A1 & Cash / Total asset - 1 & 300 & 0 & .88 & .2091 & .18456 \\
\hline CA_CL & $\begin{array}{l}\text { Current assets / Current } \\
\text { liabilities }\end{array}$ & 300 & .02 & 31.99 & 2.7156 & 3.15632 \\
\hline CA_CL1 & $\begin{array}{l}\text { Current assets / Current } \\
\text { liabilities }-1\end{array}$ & 300 & .01 & 26.51 & 2.7648 & 2.93711 \\
\hline CA_A & Current assets / Total assets & 300 & .04 & 1.00 & .5876 & .22893 \\
\hline CA_A1 & $\begin{array}{l}\text { Current assets / Total assets } \\
-1\end{array}$ & 300 & .04 & .99 & .5844 & .23206 \\
\hline CA_SAL & Current assets / Sales & 299 & .03 & 81.79 & 1.7277 & 5.49972 \\
\hline CA_SAL1 & Current assets / Sales - 1 & 299 & .01 & 113.89 & 1.7283 & 6.90768 \\
\hline CL_E & Current liabilities / Equity & 300 & -171.4 & 36.32 & .0948 & 10.32491 \\
\hline CL_E1 & Current liabilities / Equity - 1 & 300 & -5.52 & 36.32 & .8132 & 3.16743 \\
\hline RD_A & $\mathrm{R} \& \mathrm{D} /$ Total assets & 298 & 0 & 2151.26 & 15.768 & 139.76863 \\
\hline RD_A1 & $\mathrm{R} \& \mathrm{D} /$ Total assets -1 & 298 & 0 & 2204.48 & 14.413 & 137.25719 \\
\hline RD_SAL & R\&D / Sales & 297 & 0 & 79061.1 & 272.77 & 4587.37140 \\
\hline RD_SAL1 & R\&D / Sales - 1 & 297 & 0 & 81017.0 & 282.31 & 4700.93926 \\
\hline RDCAP & RD Capital / Total assets & 297 & 0 & 23282.0 & 439.22 & 2200.31142 \\
\hline $\mathrm{N}$ valid & Bnkrpty File Dt & 286 & & & & \\
\hline
\end{tabular}

The minimum and maximum values for each variable for bankrupts and non-bankrupts are presented in Table 5 .

Table 5. Minimum and maximum values separately for bankrupts and non-bankrupts

\begin{tabular}{|c|c|c|c|c|}
\hline \multirow{2}{*}{ Variable } & \multicolumn{2}{|c|}{ Bankrupt } & \multicolumn{2}{|c|}{ Non-bankrupt } \\
\hline & Min & $\operatorname{Max}$ & Min & $\operatorname{Max}$ \\
\hline GROW_NS & -0.88112 & 4.926324 & -0.56961 & 11.5467 \\
\hline GROW_NS1 & -3.67774 & 4.926324 & -0.88024 & 3.094905 \\
\hline SAL_TA & 0 & 5.685619 & 0.02721 & 8.061818 \\
\hline SAL_TA1 & 0 & 18.48214 & 0.007803 & 8.061818 \\
\hline NP_E & -683.041 & 11.7094 & -172.632 & 210.3704 \\
\hline NP_E1 & -14.813 & 11.7094 & -172.632 & 0.873351 \\
\hline NP_A & -11.9189 & 3.63125 & -3.24752 & 0.323625 \\
\hline NP_A1 & -19.188 & 3.63125 & -3.24752 & 0.323625 \\
\hline GP_SAL & -2.9 & 5.647026 & -0.11614 & 0.966102 \\
\hline GP_SAL1 & -2.9 & 5.647026 & -0.11614 & 0.960938 \\
\hline
\end{tabular}




\begin{tabular}{|c|c|c|c|c|}
\hline \multirow{2}{*}{ Variable } & \multicolumn{2}{|c|}{ Bankrupt } & \multicolumn{2}{|c|}{ Non-bankrupt } \\
\hline & Min & $\operatorname{Max}$ & Min & $\operatorname{Max}$ \\
\hline NP_SAL & -357.835 & 1.607192 & -50.2368 & 0.613509 \\
\hline NP_SAL1 & -357.835 & 1.607192 & -56.362 & 1.027454 \\
\hline E_FA & -2485 & 311.5442 & -195.592 & 433.3333 \\
\hline E_FA1 & -161.481 & 311.5442 & -195.592 & 433.3333 \\
\hline WC_A & -11.9957 & 0.726 & -9.10191 & 0.859479 \\
\hline WC_A1 & -17.3644 & 0.706875 & -9.10191 & 0.855117 \\
\hline L_E & -16.1891 & 22.6082 & -171.481 & 52.2807 \\
\hline L_E1 & -12.4957 & 22.6082 & -1.07746 & 55.86709 \\
\hline $\mathrm{L}_{-} \mathrm{A}$ & 0.037827 & 14.12834 & 0.011731 & 13.56984 \\
\hline L_A1 & 0.096296 & 18.05416 & 0.011434 & 13.56984 \\
\hline CASH_CL & 0 & 13.36595 & 0.006046 & 19.60759 \\
\hline CASH_CL1 & 0 & 7.490566 & 0.006046 & 25.57322 \\
\hline CASH_A & 0 & 0.840932 & 0.004492 & 0.882122 \\
\hline CASH_A1 & 0 & 0.840932 & 0.005389 & 0.882122 \\
\hline CA_CL & 0.019171 & 16.64209 & 0.049778 & 31.99091 \\
\hline CA_CL1 & 0.01245 & 10.16735 & 0.049778 & 26.51117 \\
\hline CA_A & 0.040431 & 0.99894 & 0.059751 & 0.972441 \\
\hline CA_A1 & 0.040431 & 0.987842 & 0.047756 & 0.978232 \\
\hline CA_SAL & 0.030588 & 81.78959 & 0.059144 & 9.214689 \\
\hline CA_SAL1 & 0.007488 & 22.4529 & 0.059144 & 113.889 \\
\hline CL_E & -16.161 & 12.12195 & -171.481 & 36.31579 \\
\hline CL_E1 & -5.51718 & 12.12195 & -0.76056 & 36.31579 \\
\hline RD_A & 0 & 4.174721 & 0 & 2151.261 \\
\hline RD_A1 & 0 & 4.174721 & 0 & 2204.482 \\
\hline RD_SAL & 0 & 77.4717 & 0 & 79061.15 \\
\hline RD_SAL1 & 0 & 77.4717 & 0 & 81017.09 \\
\hline RDCAP & 0 & 892.4 & 0 & 23282 \\
\hline
\end{tabular}

All factors which have the negative anticipated relationship with bankruptcy probability demonstrated less minimum values for bankrupts than for non-bankrupts. Variables which have the positive connection: L_A and L_E have less value for non-bankrupts, which is logically reasonable. There is not the same regularity as for the maximum means, but overall non-bankrupts has a higher value for the factors which have a negative anticipated impact on financial distress probability (with the exception of such variables as CA_SAL and CA_A, which represent liquidity). It is also necessary to notice that non-bankrupts have much greater values for parameters which characterise $\mathrm{R} \& \mathrm{D}$ ex- penditure. This may constitute the signal that R\&D has a negative impact on bankruptcy probability.

\section{Econometric analysis and results Data treatment}

Our empirical analysis began with data processing. The raw data contains a lot of missing values. The data division between the bankrupts and non-bankrupts of each year of the analysing period have also been provided. The next step is the calculation of financial ratios for the year of bankruptcy and a year earlier. Only R\&D capital scaled 
by total assets was calculated for the current year, because this parameter has already contained information about the R\&D expenditure of previous years. The emission data analysis does not make sense, because the neural network methodology does not require it. The final sample contains 286 valid observations: 14 were excluded by the algorithm. For the data analysis, the computer program IBM SPSS statistics has been used.

\section{Neural network configuration selection}

Two architecture types have been tested in the article: RBF and MLP. The first step was to define the best architecture type or its combination to solve the particular problem. The main parameters which aid in selecting the model are the percentage of correctly predicted bankrupts, non-bankrupts, and the error function value. We analysed the following combinations of network architectures:

The classical MLP network for all factors described in chapter II, which have been automatically set by the program. Predictive results are outlined below. The model quality is very high: the cross-entropy function produced a very low value; the percentage of correctly predicted companies is high: $98.8 \%$ for non-bankrupts and $87.5 \%$ for bankrupts on the tested sample (Table 6).

Table 6. Classical MLP model results

\begin{tabular}{|c|c|c|}
\hline \multicolumn{3}{|c|}{ Model Results } \\
\hline \multirow{3}{*}{ Learning } & Error: cross entropy & 6.596 \\
\hline & Incorrect prediction & $0.5 \%$ \\
\hline & Learning time & 0:00:00.08 \\
\hline
\end{tabular}

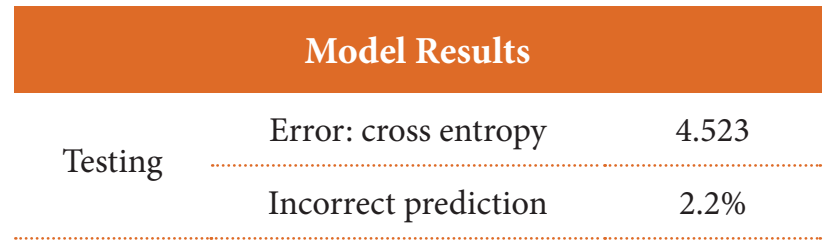

The radial basis function algorithm (RBF) was also run for all factors. The 8-neurons RBF demonstrated a lower predictive ability: $93.8 \%$ for non-bankrupts and $72.7 \%$ for the bankrupts on the tested sample with more prevalent errors than in the previous case. It may be noted that this model is worse overall in terms of all the applied parameters (Table 7).

Table 7. RBF results

\section{Model Results}

$\begin{array}{lcc} & \text { Error: sum of squares } & 15.662 \\ \text { Learning } & \text { Incorrect prediction } & 11.3 \% \\ & \text { Learning time } & 0: 00: 01.69 \\ & \text { Error: sum of squares } & 4.864^{\mathrm{a}} \\ \text { Testing } & \text { Incorrect prediction } & 8.7 \%\end{array}$

The MLP with only important parameters (2-step MLP). According to this model the most important factors showed by the first MLP model were included in the network. They are introduced below. The program has automatically selected the optimal algorithm, but the accuracy is lower than in case 1 above: $100 \%$ accuracy for non-bankrupts and $67.5 \%$ for bankrupts. The model quality is also lower than for MLP with all factors (Figure 2).

Figure 2. Normalised Importance for RBF

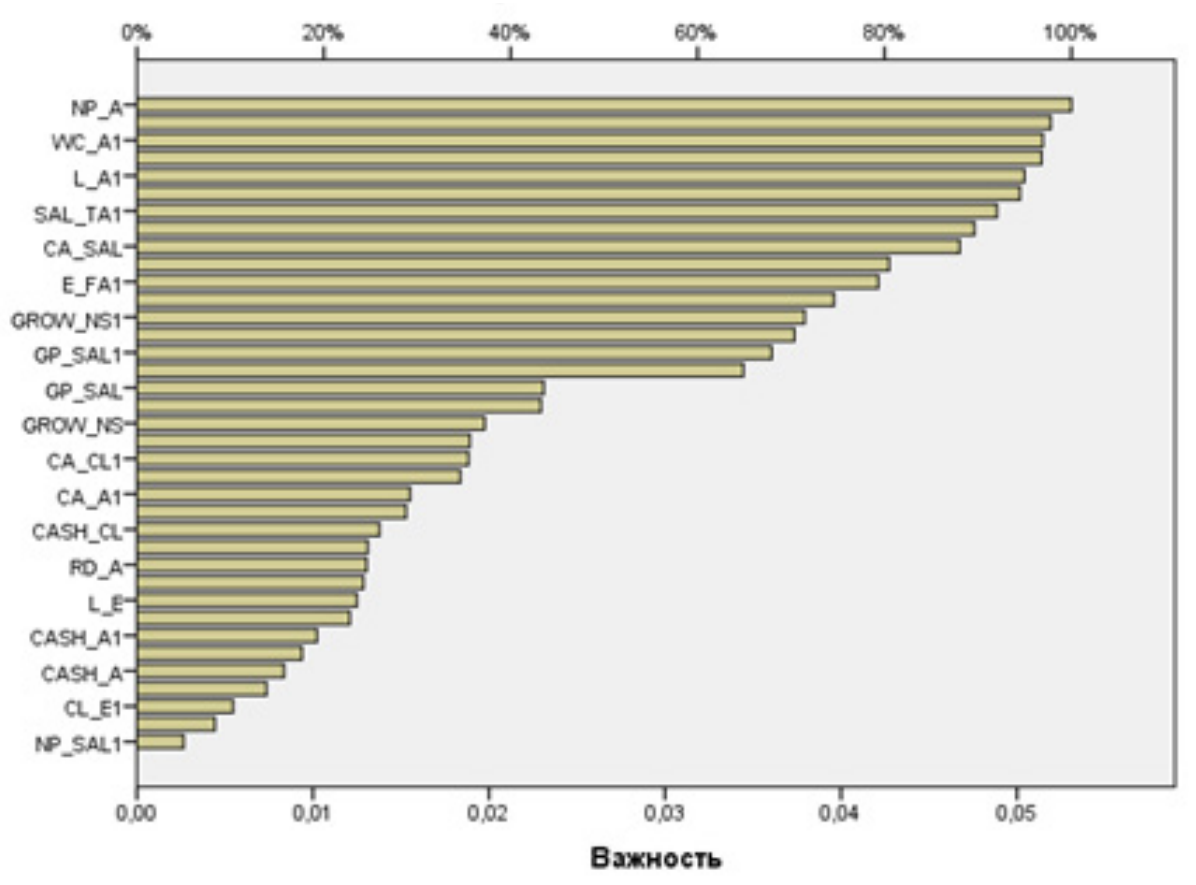


The RBF with the most important factors, selected by MLP (MLP-RBF). It is known that RBF can predict better with low quantity of input variables. As was stated below, the high dimension dramatically decreases the model quality of RBF. To improve this model, the selection algorithm based on MLP was used. This network demonstrated the lowest result from all models. The error function value is also very large (Table 8 ).

Table 8. MLP_RBF results

$\begin{array}{ccc} & \text { Model Results } & \\ & \text { Error: sum of squares } & 18.878 \\ \text { Learning } & \text { Incorrect prediction } & 11.8 \% \\ & \text { Learning time } & 0: 00: 00.85 \\ \text { Testing } & \text { Error: sum of squares } & 7.435^{\mathrm{a}} \\ & \text { Incorrect prediction } & 13.0 \%\end{array}$

The MLP and RBF, using separate factors for the year of bankruptcy and one year before the bankruptcy. There are 4 different models in total. We do not need to describe all these neural networks in detail because all of them demonstrated a much lower quality of model and predictive accuracy. It is necessary to check the decreased dimension models, because in some cases this can improve the result, but according to analysed data it did not produce a positive result.

The analysis which has been run above allows us to conclude that the MLP neural networks are better than the $\mathrm{RBF}$ for this particular issue. The main reason is that the number of the factors is rather large, while the methods of dimension decreasing did not improve the results. Another question is the usage of probabilistic neural network (PNN), which was created for solving classification issues. This approach has an RBF framework, and consequently is inappropriate for the present study, which involves a great number of input factors.

\section{MLP architecture selection}

It was decided that simple MLP is the best approach to analysing innovative company bankruptcy probability. MLP can have different kinds of architecture, and for this study all combinations were tested, and the best performing were selected. We can vary the following parameters: the activation function on the hidden layer, on the output layer, the number of the hidden levels, the quantity of neurons on each level. The activation function on the hidden level can be the hyperbolic tangent or sigmoid. The choice of activation function on the output layer is wider, and to that end, to the previous two functions were added identical and softmax functions. For the sake of convenience, all these functions are introduced in Table 9.
Table 9. Activation function types

\section{Activation \\ function \\ Description}

Identical $\quad \mathrm{F}(\mathrm{x})=\mathrm{x}$

$\begin{array}{ll}\text { Sigmoid } & \mathrm{f}(\mathrm{x})=\left(1+\mathrm{e}^{-\mathrm{x}}\right)^{-\mathrm{a}}, \\ & a>0 \text {, The most common function of } \\ \text { this type is logistic function }\end{array}$

$\begin{aligned} & \text { Hyperbolic } \\ & \text { tangent }\end{aligned} \quad \mathrm{f}(\mathrm{x})=\frac{\left(\mathrm{e}^{\mathrm{x}}-\mathrm{e}^{-\mathrm{x}}\right)}{\left(\mathrm{e}^{\mathrm{x}}+\mathrm{e}^{-\mathrm{x}}\right)}$

$$
f_{i}(x)=\frac{e^{x_{i}}}{\sum_{i=1}^{J} e^{x_{i}}}, i=1, \ldots, J
$$

Softmax

This is generalised for multidimensional case of sigmoid function. In some case it can help to maintain better model quality.

It may be supposed that the identical function is worse than others for output layer activation function because of non-trivial dependence. For the completeness of the analysis all these functions have been tested.

Another parameter which can be variable in its effects is the layer quantity. For the purposes of forecasting, one or two hidden layers are used. After more than 200 iterations, two optimal configurations of architecture were defined.

MLP with one 4-neuron hidden layer, activation function for hidden layer is hyperbolic tangent, and for output layer Softmax is used. The correctly predicted variables are presented in Table 10. The cross-entropy value is 6.6 for the testing sample and 4.5 for tested. This small error value indicates that the quality of the model is excellent. Moreover, reducing the error value is an excellent feature of network power prediction.

Table 10. One hidden layer MLP results

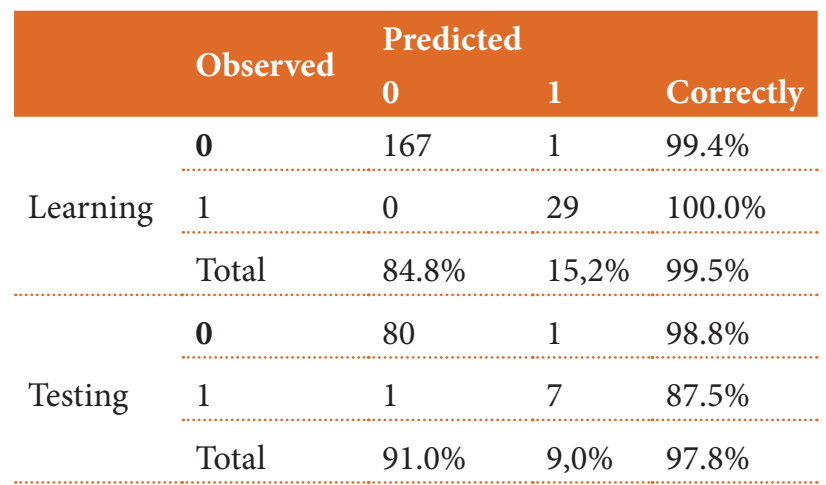


The most important factors are from all the main divisions of economic parameters of a company: profitability, effectiveness, sustainability, liquidity and innovativeness. They are arranged in descending order of importance in terms of predictions, but all of them are included in the top set of values. The neuron weights for the most significant factors are presented in Table 11.

Table 11. One hidden layer MLP estimations

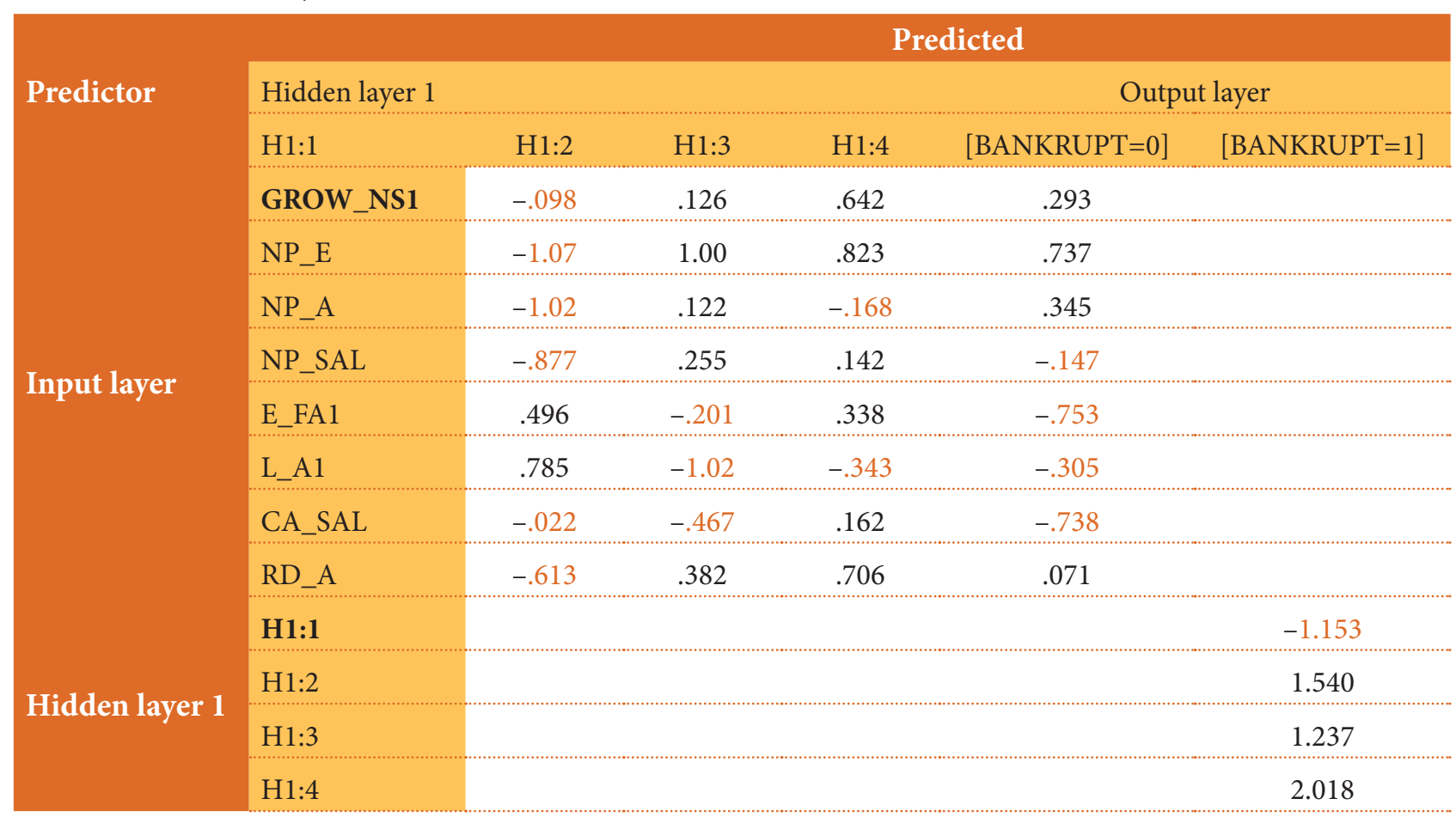

The negative mean of neuron weight means that the increasing value of input mean decreases the output value. On the other hand, it reflects negative relationships between the dependent variable and a covariate. The positive value indicates a positive relationship. We shall here explore in detail the defining of dependence between NP_E and bankruptcy probability. The neuron on the hidden layer, which has a positive relationship with higher financial distress probability is $\mathrm{H}(1: 1)$, because of its positive value, other neurons have a negative impact. The NP_E has a strictly negative correlation with neuron $\mathrm{H}$ (1:1). It can be concluded that NP_E has a negative connection with bankruptcy probability. It means that the variable NP_E and the company's profitability is the factor which decreases the bankruptcy probability. NP_A and NP_SAL, which also reflect profitability, have the overall effect of decreasing distress probability. The GROW_NS1, which reflects the firm's effectiveness also has the negative relationship with bankruptcy probability. L_A and E_FA1 are the variables from the sustainability sector, but the higher mean corresponds to lower sustainability. The dependence of these factors on bankruptcy probability is positive, and consequently the higher sustainability decreases such dependence. CA_SAL is the liquidity factor. Correspondingly to neuron weights it does not have definite influence, but the total impact is more likely positive than negative on bankruptcy probability. Nevertheless, the influence of liquidity is much less than the impact of profitability. RD_A variable is the innovativeness factor. It has a definite impact on dis- tress probability, which is negative. To sum up, according to this model of the neural network, hypotheses 1, 2 and 3 are not rejected, while hypotheses 4 and 5 are rejected.

MLP with 2 hidden layers, 5 neurons in layer one and 4 in layer two, activation function for hidden layer is sigmoid, and for output layer Softmax is used. The cross entropy is 9.128 for the learning sample and 5.097 for testing sample. It is not significantly higher than in the previous network. The total accuracy is also less overall, but the main advantage of this model is that it has the highest value for correctly predicted bankrupts $-91.7 \%$. The results of all samples are presented in Table 12.

Table 12. Results for MLP with two hidden layers

\begin{tabular}{|c|c|c|c|c|}
\hline & \multirow[t]{2}{*}{ Observed } & \multicolumn{3}{|c|}{ Predicted } \\
\hline & & 0 & 1 & Correct \\
\hline \multirow{3}{*}{ Learning } & 0 & 181 & 3 & $98.4 \%$ \\
\hline & 1 & 0 & 25 & $100.0 \%$ \\
\hline & Total & $86.6 \%$ & $13.4 \%$ & $98.6 \%$ \\
\hline \multirow{3}{*}{ Testing } & 0 & 64 & 1 & $98.5 \%$ \\
\hline & 1 & 1 & 11 & $91.7 \%$ \\
\hline & Total & $84.4 \%$ & $15.6 \%$ & $97.4 \%$ \\
\hline
\end{tabular}


The variables from profitability, liquidity, sustainability, effectiveness and innovativeness are among the most important factors in terms of prediction accuracy, but the order of importance has a different sequence than in previous models. The table listing the influence coefficients on bankruptcy for the main variables is introduced in Table 13.

Table 13. Two hidden layers MLP factor impact

\begin{tabular}{l|c} 
Factor & Influence \\
NP_E & 35.80942 \\
\hline NP_A & 54.17096 \\
\hdashline L_A & -102.832 \\
\hdashline RD_A & 28.66417 \\
\hline GROW_NS1 & 27.67251 \\
\hline NP_SAL1 & 25.55392 \\
\hline WC_A1 & 40.76026 \\
\hline
\end{tabular}

As can be noticed, profitability again negatively correlates with distress probability: NP_E, NP_A and NP_SAL1 have positive coefficients in relation to the output neurons for non-bankrupts. L_A has a negative coefficient, meaning unsustainability has a negative effect. Consequently, sustainability has a positive impact. Efficiency, Liquidity and innovativeness has also negative influence on bankruptcy probability. To sum up, profitability, effectiveness, and sustainability have a negative impact on bankruptcy probability, as was assumed in our hypothesis. Liquidity has been demonstrated to have a strictly negative impact in the second model, and to not have a strictly defined effect in the first model. As such, we can conclude that there is an overall negative impact on the likelihood of distress. The innovation hypothesis was rejected by both models, and it also has a negative connection. The representation of diapasons for the most important factors for bankrupts and non-bankrupts is presented in Table 14.

Table 14. The ranges for bankrupts and non-bankrupts for the most important variables

\begin{tabular}{|c|c|c|c|c|}
\hline \multicolumn{5}{|c|}{ NP_E } \\
\hline \multirow{2}{*}{ Range } & \multicolumn{2}{|c|}{ Bankrupt } & \multicolumn{2}{|c|}{ Non-bankrupt } \\
\hline & Frequency & Percent & Frequency & Percent \\
\hline-3.67773696 & 18 & 35,3 & 2 & 0,8 \\
\hline-1.95692485 & 1 & 2,0 & 5 & 2,0 \\
\hline-0.23611274 & 8 & 15,7 & 25 & 10,1 \\
\hline 1.48469937 & 16 & 31,4 & 215 & 86,7 \\
\hline 3.20551148 & 4 & 7,8 & 0 & 0,0 \\
\hline 4.92632358 & 4 & 7,8 & 1 & 0,4 \\
\hline & 51 & & 248 & \\
\hline
\end{tabular}

\begin{tabular}{|c|c|c|c|c|}
\hline \multicolumn{5}{|c|}{ CA_SAL } \\
\hline \multirow{2}{*}{ Range } & \multicolumn{2}{|c|}{ Bankrupt } & \multicolumn{2}{|c|}{ Non-bankrupt } \\
\hline & Frequency & Percent & Frequency & Percent \\
\hline 0.03058824 & 1 & 2,0 & 0 & 0,0 \\
\hline 16.3823882 & 45 & 90,0 & 249 & 100,0 \\
\hline 32.7341881 & 2 & 4,0 & 0 & 0,0 \\
\hline 49.085988 & 1 & 2,0 & 0 & 0,0 \\
\hline 65.4377879 & 0 & 0,0 & 0 & 0,0 \\
\hline 81.7895879 & 1 & 2,0 & 0 & 0,0 \\
\hline
\end{tabular}




\begin{tabular}{|c|c|c|c|c|}
\hline \multicolumn{5}{|c|}{$\mathbf{L}_{-} \mathbf{A}$} \\
\hline \multirow{2}{*}{ Range } & \multicolumn{2}{|c|}{ Bankrupt } & \multicolumn{2}{|c|}{ Non-bankrupt } \\
\hline & Frequency & Percent & Frequency & Percent \\
\hline 0.01173083 & 0 & 0.0 & 1 & 0.4 \\
\hline 2.83505311 & 44 & 86.3 & 247 & 99.2 \\
\hline 5.6583754 & 3 & 5.9 & 0 & 0.0 \\
\hline 8.48169768 & 0 & 0.0 & 0 & 0.0 \\
\hline 11.30502 & 1 & 2.0 & 0 & 0.0 \\
\hline \multirow[t]{2}{*}{14.1283422} & 3 & 5.9 & 1 & 0.4 \\
\hline & 51 & & 249 & \\
\hline \multicolumn{5}{|c|}{ RD_A } \\
\hline \multirow{2}{*}{ Range } & \multicolumn{2}{|c|}{ Bankrupt } & \multicolumn{2}{|c|}{ Non-bankrupt } \\
\hline & Frequency & Percent & Frequency & Percent \\
\hline 0 & 8 & 16.3 & 49 & 19.7 \\
\hline 430.252101 & 41 & 83.7 & 197 & 79.1 \\
\hline 860.504202 & 0 & 0.0 & 1 & 0.4 \\
\hline 1290.7563 & 0 & 0.0 & 1 & 0.4 \\
\hline 1721.0084 & 0 & 0.0 & 0 & 0.0 \\
\hline 2151.2605 & 0 & 0.0 & 1 & $0, .4$ \\
\hline
\end{tabular}

\begin{tabular}{|c|c|c|c|c|}
\hline \multicolumn{5}{|c|}{ GROW_NS1 } \\
\hline \multirow{2}{*}{ Range } & \multicolumn{2}{|c|}{ Bankrupt } & \multicolumn{2}{|c|}{ Non-bankrupt } \\
\hline & Frequency & Percent & Frequency & Percent \\
\hline-3.67773696 & 1 & 2.2 & 0 & 0.0 \\
\hline-1.95692485 & 0 & 0.0 & 0 & 0.0 \\
\hline-0.23611274 & 2 & 4.3 & 22 & 8.8 \\
\hline 1.48469937 & 42 & 91.3 & 226 & 90.8 \\
\hline 3.20551148 & 0 & 0.0 & 1 & 0.4 \\
\hline 4.92632358 & 1 & 2.2 & 0 & 0.0 \\
\hline & 46 & & 249 & \\
\hline
\end{tabular}


The distribution of observations across all ranges is almost the same for all the most important factors. The L_A factor which characterises a company's unsustainability is more likely greater for the bankrupt, which is logically explainable. CS_SAL presents the liquidity and it can be noticed that all non-bankrupts have almost the same level of this parameter, while for the bankrupts means are variously distributed across the ranges. We may conclude that profitability is the most important factor for NP_E as the distribution of values for bankrupts are closer to the lowest range, while healthy firms indicate a higher average mean.

\section{Checking model quality}

In the framework of this research, our model's validity needs to be approved. What are the major arguments that these two models can strongly predict distress? First, the demonstration by two different neural networks of practically identical results in terms of influence and importance allows us to conclude that the model is of high quality. Second, the values of the error function and the prediction accuracy are at a high level. But it is not enough to be confident in the quality of the model. There is one problem that remains: that dependence is obvious and a neural network is not needed to predict bankruptcy. In many articles, for example Lee, Han \& Kwon (1996) a decision tree analysis was imposed in order to exclude this possibility. In this paper the random forest analysis is provided to prove the model quality. The results are shown in Table 15.

Table 15. The random forest prediction results

\begin{tabular}{l|ccc}
\hline Model Results & Predicted \\
\hline Observed & 0 & 1 & Correctly \\
\hline 0 & 249 & 0 & $100.0 \%$ \\
\hline 1 & 51 & 0 & $0.0 \%$ \\
\hline Total & $100.0 \%$ & $0.0 \%$ & $83.0 \%$ \\
\hline Approach: CHAID & & \\
\hline
\end{tabular}

As can be seen here, $83 \%$ is the final accuracy level for the decision tree, against more than $98 \%$ by both neural networks. The quantity of correctly predicted bankrupts is zero. This fact lends credence to the argument that the neural network is a quality model with great predictive power for both categories. The final question is the choice of the most powerful model among those provided above. Both networks have great predictive power, as well as advantages and disadvantages. To receive a more accurate result for non-bankrupts the first model is preferable, while the second network is more appropriate for predicting bankruptcy.

\section{Conclusion}

In recent years, research studies on financial distress predicting have been devoted to increasing forecasting power. Many new combined methods have been invented: MDA with a neural network, more complex network configuration algorithms, networks based on a genetic algorithm, and many others. The total predictive ability of the model developed in the present research is almost $98 \%$, which corresponds to the results of the most modern methods. The multilayer perceptron gave a great result due to the correctly selected factor set and network architecture. The most important factors have been taken from the best models of the earliest research which we have analysed. Moreover, extra factors have been added which reflect the 'innovativeness' of companies, because the paper's purpose was the prediction of financial distress for innovative companies. We have applied a total of 19 factors characterising efficiency, liquidity, profitability, sustainability, and level of innovation. All these factors have been analysed over two specific years: the year before bankruptcy, and the previous one, with the exception of $\mathrm{R} \& \mathrm{D}$ capital, which was examined only for one year. We provided two models in order to cater for the most confidence in terms of obtained results. The 3-layer MLP is greater for predicting all of a company's conditions, while the 4-layer MLP is greater for bankruptcy forecasting ( $91 \%$ correctly predicted bankrupts). Both approaches demonstrated almost the same level of influence of factor groups on final bankruptcy probability. The first model demonstrates a negative impact in terms of sustainability, profitability, effectiveness, and innovativeness, and an inconclusive result in terms of liquidity. The second model demonstrates a negative influence for all factor groups. The most important factors are profitability, sustainability, and innovativeness. Additionally, the variables NP_A, NP_E, L_A, L_A1, L_E, RD_A, CA_SAL and GROW_NS1 demonstrate the highest importance.

It would be very interesting to continue the development of models for innovative companies. Possible improvements involve the following: the expansion of the sample by adding additional years before bankruptcy, the use of dynamic neural networks to analyse this data sample and the introduction of special algorithms for selecting the most appropriate factor. More accurate predictions were possible only with the use of genetic algorithms and fuzzy neural networks, but previous studies used these approaches only for data samples from non-innovative companies. It would be interesting to apply such approaches on the forecast of financial distress of an innovative company.

\section{References}

1. Altman, E. (1968). "Financial ratios, discriminant analysis and the prediction of corporate bankruptcy." The journal of finance. Vol. 23-4, 589-609.

2. Altman, E. I., Haldeman, R. G., and Narayanan, P. (1977). "ZETA Analysis a New Model to Identify Bankruptcy Risk of Corporations.” Journal of Banking \& Finance, Vol. 1, 29-54 
3. Black, F. and Scholes, M. (1973). "The pricing of options and corporate liabilities." Journal of Political Economy 81, Vol. 3, 637-654.

4. Merton, R. (1974). "On the pricing of corporate debt. The risk structure of interest rates." The Journal of Finance, Vol. 29, 449-470.

5. Reisz, A. and Perlich, C. (2004). "A market-based framework for bankruptcy prediction." SSRN, Vol. 3-2, 85-131.

6. Hillegeist, E., Keating, D. and Cram, K. (2004). "Assessing the probability of bankruptcy." Review of Accounting Studies, Vol. 9-1, 5-34

7. Bharath, S. and Shumway, T. (2004). "Forecasting default with the KMV-Merton model." SSRN Electronic Journal, Vol. 21, 484.

8. Wong, H. and Choi, T. (2009). "Estimating default barriers from market information." Quantitative Finance, Vol. 9-2, 187-196.

9. Luandres, A. and Zhdanov, A. (2013). "Investment opportunities and bankruptcy prediction." Journal of Financial Markets, Vol. 16-3, 439-476.

10. Beaver, W (1966). "Financial ratios as predictors of failure." Journal of Accounting Research, Vol. 4, 71-111.

11. Ohlson, J. (1980). "Financial ratios and the probabilistic prediction of bankruptcy." Journal of Accounting Research, Vol. 18-1, 109-131.

12. Odom, M. and Sharda, R. (1990). "A neural network model for bankruptcy prediction." International Joint Conference on Neural Networks, Vol. 2, 163-168.

13. Berry, R. and Treigueiros, D. (1991). “The Application of Neural Network Based Methods to the Extraction of Knowledge from Accounting Reports." IEEE International Joint Conference on Neural Networks, 136-146.

14. Coakley, J. and Brown, C. (1991). "Neural Networks Applied to Ratio Analysis in the Analytical Review Process." The $4^{\text {th }}$ International Symposium on Expert Systems in Accounting, Finance and Management, Vol 1, 35 .

15. Chung, H. and Tam, K. (1992). "Comparative Analysis of Inductive- Learning Algorithm.” Intelligent Systems in Accounting, Finance and Management, John Wiley \& Sons, Ltd., Vol. 2-1, pages 3-18.

16. Lee, K., Han, I. and Kwon, Y. (1996). "Hybrid neural network models for bankruptcy predictions." Decision Support Systems, Vol. 18(1 SPEC. ISS.), 63-72.

17. Jo, H., Han, I. and Lee, H. (1997). “Bankruptcy prediction using case-based reasoning, neural networks, and discriminant analysis." Expert Systems with Applications, Vol. 13-2, 97-108.
18. Yang, Z., Platt, M. and Platt, H. (1999). "Probabilistic Neural Networks in Bankruptcy Prediction.” Journal of Business Research J Busn Res Z. R. Yang, Vol. 4444-97, 67-74.

19. Chris Charalambous \& Andreas Charitou \& Froso Kaourou, 2000. "Comparative Analysis of Artificial Neural Network Models: Application in Bankruptcy Prediction," Annals of Operations Research, Springer, vol. 99(1), 403-425.

20. Olmeda, I. and Fernandez, E. (1997). "Hybrid Classifiers for Financial Multicriteria Decision Making. The Case of Bankruptcy Prediction." Computational Economics, Vol. 10-4, 317-352.

21. Piramuthu, S., Raghavan, H. and Shaw, M. (1998). "Using Feature Construction to Improve the Performance of Neural Networks." Management Science, Vol. 44-2. 416-430.

22. Zhang, W. (2005). "R\&D investment and distress risk. Journal of Empirical Finance”, Vol. 32-C, pp. 94-114.

23. Koh, H.C., and Tan, S.S., 1999, A Neural Network Approach to the Prediction of Going Concern Status, Accounting and Business Research, Vol. 29,No. 3, pp. 211-216.

24. Yim, J., Mitchell, H. 'A Comparison of Corporate Distress Prediction Models in Brazil: Hybrid Neural Networks, Logit Models and Discriminant Analysis," Nova Economia, vol. 15(1), 2005, pp. 73-93

25. Virag, M., Kristof, T. and Kristof, M. (2005). "Neural Networks in Bankruptcy Prediction - a Comparative Study on the Basis of the First Hungarian Bankruptcy Model." Actaoeconomica, Vol. 55-4, 403-426.

26. Tsai, C. and Wu, J. (2008). "Using neural network ensembles for bankruptcy prediction and credit scoring." Expert Systems with Applications, Vol. 34-4, 2639-2649.

27. Kim, M. and Kang, D. (2010). "Ensemble with neural networks for bankruptcy prediction.” Expert Systems with Applications, Vol. 37-4, 3373-3379.

28. Zhou, L., Lai, K.K., Yu, L. 'Least squares support vector machines ensemble models for credit scoring." (2010). Expert Systems with Applications, Vol. 37(1) p. 127-133

29. Kasgari, A., Divsalar, M., Javid, M., and Ebrahimian, S. (2013). "Prediction of bankruptcy Iranian corporations through artificial neural network and Probit-based analyses." Neural Computing and Applications, Vol. 23(3-4), 927-936.

30. Makeeva, E., Bakurova, A. (2012). "Forecasting Bankruptcy of Oil and Gas Companies Using Neural Networks." Journal of Corporate Finance Research, Vol. 3-23, 22-30. 
31. Yasnitsky, L., Ivanov, D., Lipatova, E. (2014). "Neural Network System for Assessing the Likelihood of Bank Bankruptcy”. Business Informatics. Vol. 3., 49-56.

32. Azayite, F. and Achchab, S. (2016). "Hybrid Discriminant Neural Networks for Bankruptcy Prediction and Risk Scoring." Procedia Computer Science, Vol. 83, 670-674.

33. Azadnia, A., Siahi, A. and Motameni, M. (2017). "An Adaptive Fuzzy Neural Network Model for Bankruptcy Prediction of Listed Companies on the Tehran Stock Exchange." International Journal of Engineering, Vol. 30-12, 1879-1884.

34. Makeeva, E., Khugaeva, M. (2018). "Evaluation of financial distress costs of innovative companies." Russian Management Journal, Vol. 16-1. 37-62.

35. 35. Opler, T., Titman, S. (1994) "Financial distress and corporate performance", The Journal of Finance, Vol. 49-3, 1015-1040.

36. 36. Buddelmeyer, H., Jensen P., and Webster E. (2010). "Innovation and the determinants of company survival." Oxford Economic Papers, Vol. 62, 261-285.

Contribution of the authors: the authors contributed equally to this article.

The authors declare no conflicts of interests.

The article was submitted 20.11.2021; approved after reviewing 22.11.2021; accepted for publication 24.11.2021. 